\title{
KELANGSUNGAN DAN PERUBAHAN TARI SEDULANG SETUDUNG KABUPATEN BANYUASIN
}

\author{
Rian Ardiansyah \\ Institut Seni Indonesia (ISI) Surakarta \\ Jln. Ki Hadjar Dewantara 19 Kentingan, Jebres, Surakarta 57126 \\ Dwiyasmono \\ Institut Seni Indonesia (ISI) Surakarta
}

\begin{abstract}
Setulang Setudung dance is a guest welcoming dance which is located in Banyuasin District. Since this dance was created in 2002 it already go through some developments and still on going until now. The purpose of this research is to uncover about the causative factors of Setulang Setudung dance continuity and changes in Banyuasin District. This research is using a qualitative kind of research. The process of the data collection has involve observations, interviews and documentations. The results of this research showing the present form of Setulan Setudung dance which is including moves, musics, costume and make up, also properties. Beside that, the results of this research is that Setulan Setudung dance still on goin until now and already going through cange because of the art response against the existing challenges such as the impact of oustiders culture, government, economy and education.
\end{abstract}

Keywords: Sedulang Setudung dance, continuity, and Dance Change.

\section{PENDAHULUAN}

Tari Sedulang Setudung merupakan Tari Penyambutan yang disajikan bagi tamu-tamu yang datang ke Banyuasin, sebagai tanda penghormatan. Disajikan dengan sekapur sirih dan penuh makna dalam tiap gerak dan properti yang digunakan, yaitu menceritakan tentang kekayaan alam dan mata pencaharian yang ada di Banyuasin, ibaratnya seperti memperkenalkan dengan masyarakat atau tamu yang datang (wawancara: Sari, 17 April 2019).

Tari Pesembahan Sedulang Setudung diciptakan saat pemekaran kabupaten Musi
Banyuasin dan Kabupaten Banyuasin pada tanggal 2 Juli 2002. Pada saat itu Pangkalan Balai resmi menjadi ibukota Kabupaten Banyuasin. Bupati Banyuasin sebagai pemimpin Kabupaten Banyuasin menginginkan adanya sebuah tari persembahan atau tari penyambutan tamu yang datang atau berkunjung ke Kabupaten Banyuasin sebagai bentuk penghormatan dari masyarakat Kabupaten Banyuasin. Pada saat itu, Kabupaten Banyuasin belum memiliki tari persembahan, karena tari yang biasa ditarikan adalah tari "Stabiek" yang berasal dari Kabupaten Musi Banyuasin. Pada saat itu pelopor pendiri Kabupaten 
Banyuasin yaitu Bas Amin, Adnan. AS, dan Noer Muhammad meminta pada Raden Gunawan sebagai seniman dari Kabupaten Banyuasin diminta untuk membuat sebuah tari penyambutan tamu dalam waktu satu minggu dengan peralatan seadanya (Gunawan, 2013: 8).

Kesenian adalah perwujudan gagasan dan perasaan seseorang yang tidak pernah bebas dari pengaruh masyarakat dan kebudayaan yang membesarkannya (Koentjaraningrat (1985: 204). hal tersebut dapat diartikan bahwa seni dan masyarakat merupakan satu kesatuan yang tidak dapat dipisahkan. Tari Sedulang Setudung juga tidak dapat terpisahkan dengan masyarakat Kabupaten Banyuasin sehingga menjadi bagian dari masyarakat itu sendiri.

Mempertahankan dari kelangsungan sebuah pertunjukan dalam seni biasanya terjadi sebuah perubahan baik itu dalam bentuk pertunjukanya, makna bahkan fungsi pertunjukan tersebut. Perubahan tersebut biasanya dilakukan untuk menjaga kelangsungan sebuah seni pertunjukan tersebut agar tetap berlangsung dan dapat memenuhi kebutuhan masyarakat akan seni pertunjukan. Begitu juga hal nya pada tari Sedulang Setudung di Kabupaten Banyuasin.

Seiring berjalan nya waktu tari Sedulang Setudung yang pada awalnya diciptakan hanya untuk tari persembahan saja atau tari penyambutan tamu besar saja dan ditarikan oleh 10 orang penari yang terdiri dari 7 orang penari putri dan 3 orang penari putra. Kemudian untuk menjaga kelangsungan tari tersebut maka terjadi beberapa perubahan dalam bentuk pertunjukanya seperti gerak, properti, rias dan busana. Perubahan yang terjadi pada tari
Sedulang Setudung dilakukan agar tari tersebut tidak hanya ditarikan di dalam acara-acara besar pemerintahan saja tetapi tari ini bisa ditarikan diberbagai acara yang ada di masyarakat atau bisa dinikmatioleh masyarakat banyuasin dan tarian ini juga bisa ditampilkan di dalam acara seperti acara pernikahan, khitanan dan syukuran.

Perubahan pertunjukan tari Sedulang Setudung ada pada jumlah penari dan properti yang digunakan. Pertunjukan tari sedulang setudung saat ini selain bisa ditarikan oleh 10 orang penari bisa juga di tarikan oleh 7 orang penari putri saja, 5 orang penari putri dan 3 orang penari putri kemudian properti yang digunakan juga bisa memakai properti lengkap tepak sirih, prindon, tombak kujur, tombak serampang dan payung atau hanya tepak sirih saja atau bahkan tarian ini juga bisa ditarikan tanpa menggunakan properti.

\section{BENTUK TARI SEDULANG SETUDUNG}

Gendhon Humardani yang berpendapat bahwa bentuk ungkapan suatu karya seni pada hakekatnya bersifat fisik, seperti garis, warna, suara manusia, bunyibunyi alat, gerak tubuh, kata dan lainnya (Rustopo, 2001:111). Bentuk fisik dapat diartikan sesuatu yang bisa ditangkap oleh indera manusia, yang meliputi: gerak, musik, rias dan busana, dan properti.

\section{GERAK}

Raden Gunawan mengatakan gerakgerak di Sedulang Setudung Gerak dalam tari Sedulang Setudung merupakan gambaran dari kekhasan kebudayaan dari daerah Kabupaten Banyuasin dan gerakgerak yang ada tersebut merupakan penggambaran kegiatan dari masyarakat 
Kabupaten Banyuasin seperti mata pencaharian yaitu sebagai petani karet, sawit dan nelayan. Tari Sedulang Setudung juga terbagi menjadi 3 bagian yaitu bagian awal, bagian tengah dan bagian akhir.

\section{GERAK TARI BAGIAN AWAL}

Gerak tari bagian awal pada tari Sedulang Setudung terdiri dari gerak masuk, gerak hormat borobudur, gerak jalan ngeset awal, gerak borobudur duduk, dan gerak hormat awal.

\section{GERAK TARI BAGIAN TENGAH}

Gerak tari bagian tengah pada tari Sedulang Setudung meliputi: Kecubung Bawah Kanan, Kecubung Bawah Kiri, Do'a Tolak Balak Kanan, Do'a Tolak Bala Kiri, Rentang Bawah Kanan, Rentang Bawah Kiri, Nabe' Bawah Kanan, Nabe' Bawah Kiri, Ulur Pancing Naik, Jerembe Miring Kanan, Jerembe Miring Kiri, Sawit Kanan, Sawit Kiri, Ngayun Kiri, Mantang Kanan, Ngayun Kanan, Mantang Kiri, Rentang Atas Kanan, Rentang Atas Kiri, Ngangkit Kanan, Nabe' Atas Kiri, dan Perahu Rejung (Ngayo).

\section{GERAK TARI BAGIAN AKHIR}

Gerak tari pada bagian akhir yaitu gerak Tarik Pancing Turun, Sembahan Akhir, Jalan Ngeset Akhir, Borobudur Hormat, dan Gerak Ke Luar.

\section{MUSIK}

Musik dalam tari Sedulang Setudung yaitu gabungan dari beberapa intrumen sehingga menjadi musik yang harmonis. Adapun instrumen yang digunakan ialah akordeon, gong, gendang melayu, dol, drum, keyboard, gitar listrik, bass, dan biola.

\section{RIAS DAN BUSANA}

Penari putri di dalam tari Sedulang Setudung yaitu memakai aesan pasangkong yang terdiri dari : kain Songket, Baju Kurung, Teratai, Kalung Kebo Munggah, Pending, Kain Pelangi, Slempang, Gelang Kano, Gelang Gepeng, Gelang Sempuru, Gelang Lengan, Antingan Bulan Bintang, Gelong Malang, Bunga Rampai, Gunungan, Kelapa Setandan, Beringin, Cempako, Bunga Melati, Gandek, Sumping, Mahkota Pasangkong, Tebeng, Kalung Sbuk, Tanggai, Pelis.

Penari putra dalam tari Sedung Setudung menggunakan: Baju dalaman, Baju Jubah, Celana, Badong, Rumpak, Tanjak, Terompah/Sepatu.

\section{PROPERTI}

Di dalam tari sedulang setudung apabila tari ini dipentaskan untuk menyambut tamu besar pemerintahan maka setiap penari membawa properti atau peralatan tari baik itu penari putri maupun penari putra. Sedangkan untuk pementasan biasa atau pernikahan biasanya hanya penari primadona yang membawa properti tari atau tidak menggunakan properti sama sekali. Berikut properti di dalam pertunjukan tari sedulang setudung:

a. Sekapur Sirih yang diletakan di dalam tepak dan dibawa oleh penari primadona dan di buka oleh pennari ketiga untuk di berikan ke tamu undangan.

b. Prindon yang dibawa oleh penari kedua untuk menampung air ludah tamu undangan yang mencicipi sekapur sirih.

c. Bubu (alat penangkap ikan) dibawa oleh penari ke empat sebagai simbol salah satu mata pencaharian masyarakat banyuasin yaitu menangkap ikan di sungai menggunakan bubu. 
d. Senik yaitu keranjang terbuat dari lidih pohon nipah dan berisikan padi, biji pohon karet dan buah sawit yang dibawa penari kelima sebagai simbol mata pencaharian masyarakat banyuasin yaitu petani, karet dan sawit.

e. Mangkok dari kuningan berisi beras kunyit yang dibawa oleh penari ke enam dan ke tujuh, beras tersebut untuk di taburkan oleh penari yang di simbolkan sebagai rasa syukur kepada Tuhan dan bentuk penghormatan terhadap tamu undangan yang datang.

f. Payung yang dibawa penari putra pertama untuk melindungi penari primadona yang membawa sekapur sirih untuk di suguhkan kepada tamu undangan yang datang.

g. Tombak kujur yang dibawa penari putra kedua sebagai simbol perlindungan terhadap penari dan tamu undangan yang datang.

h. Tombak serampang yang dibawa penari putra ketiga sebagai simbol perlindungan terhadap penari dan tamu undangan yang datang.

\section{KELANGSUNGAN DAN PERUBAHAN TARI SEDULANG SETUDUNG}

Kesenian bukan hanya sekedar hasil kreativitas dari manusia, akan tetapi merupakan bagian dari budaya yang hidup dalam masyarakat itu sendiri. Munculnya upaya dari seniman dalam menghidupkan sebuah kesenian di daerahnya terjadi karena adanya pengaruh-pengaruh yang memungkinkan timpangnya keseimbangan. Hal tersebut terjadi akibat pandangan masyarakat yang mengangap hal-hal yang baru sebagai suau kemajuan. Masyarakat yang mengalami kejenuhan atau kebosanan sudah layaknya disuguhkan dengan perubahan, dengan begitu adanya masyarakat yang menganggap sesuatu yang jenuh dan bosan tersebut lebih menghargai kesenian di daerahnya.

Perkembangan tari merupakan sebagai sebuah respons terhadap tantangan dan dalam hal ini perkembangan masyarakat, maka akan terjadi sebuah perubahan dan kelangsungan dari sebuah organisasiatau kesenian tersebut (Slamet, 2014; 24).

Tari Sedulang Setudung telah mengalami perkembangan sejak awal diciptakan pada tahun 2002 hingga saat ini. Perkembangan tersebut terjadi pada bentuk pertunjukan tari Sedulang Setudung seperti gerak, musik, property dan busana tari. Perubahan yang terjadi pada tari Sedulang Setudung merupakan bentuk dari sebuah respons tari ini terhadap beberapa faktor yang ada demi sebuah keberlangsungan. Faktor-faktor tersebut ialah faktor internal dan faktor eksternal. Berikut faktor faktor yang mempengaruhi kelangsungan dan perubahan tari Sedulang Setudung.

\section{FAKTOR INTERNAL}

Menurut Robert Redfield yang dikutip slamet mengatakan bahwa Faktor internal yaitu aktivitas dan kreativitas para pendukungnya, terutama seniman (Slamet, 2014; 20-21). Faktor internal merupakan faktor dari dalam dan tempat berkembangnya kebudayaan tersebut. Faktor internal menjadi salah satu faktor tari Sedulang Setudung mengalami keberlangsungan dan perubahan di Kabupaten Banyuasin.

Keberlangsungan dan perubahan tari Sedulang Setudung di Kabupaten 
Banyuasin tidak lepas dari kreativitas seniman atau pencipta terhadap tari Sedulang Setudung. Di dalam tari ini Seniman atau pencipta tari melakukan beberapa perubahan terhadap bentuk pertunjukan tari. Seniman atau pencipta tari melakukan perubahan tersebut untuk keberlangusangan tari Sedulang Setudung di Kabupaten Banyuasin agar penonton tidak bosan dengan bentuk pertunjukan tari ini.

\section{FAKTOR EKSTERNAL}

Faktor eksternal merupakan faktor dari luar sebuah kesenian tersebut. Dalam tari Sedulang Setudung faktor eksternal juga berperan penting dalam keberlangsungan dan perubahan tari Sedulang Setudung di Kabupaten Bnayuasin. Faktor ini merupakan kebalikan dari faktor internal, yaitu unsur-unsur yang di luar dari kesenian tersebut, namun ikut berpatisipasi dalam perkembangan tari tersebut.

Pemerintah Kabupaten Banyuasin sangat berpengaruh terhadap keberlangsungan tari Sedulang Setudung di Kabupaten Banyuasin. Dari hasil wawancara peneliti dengan narasumber Raden Gunawan sebagai Kepala Bidang Kebudayaan Kabupaten Banyuasin beliau mengatakan bahwa Bupati Banyuasin mengeluarkan perintah secara tidak tertulis bahwa setiap ada acara di lingkungan Kabupaten Banyuasin dan instansi-instansi lainya tari sedulang setudung harus ada baik itu sebagai penyambutan tamu maupun sebagai acara pembuka, selain itu pemerintah Kabupaten Banyuasin khusus nya bidang Kebudayaan telah mengadakan workshop tari Sedulang Setudung ke 20 Kecamatan yang ada di Kabupaten Banyuasin pada tahun 2011, selain itu Dinas
Kebudayaan pernah mengadakan lomba tari sambut Sedulang Setudung antar Kecamatan dan sanggar se Kabupaten Banyuasin pada tahun 2012 dan 2013 di Tanah Mas dan pangkalan Balai (wawancara: Gunawan, 22 November 2019).

Banyaknya permintaan masyarakat akan tari ini juga berpengaruh dalam keberlangsungan tari ini karena banyak masyarakat yang menginginkan tari Sedulang Setudung ini ditampilkan dalam acara-acara pernikahan, khitanan syukuran dan lain sebagainya sebagai tari sambut maupun sebagai tari pembuka.

Faktor ekonomi juga berpengharu dengan eksistensinya tari Sedulang Setudung hal terbut di karenakan dengan banyak nya permintaan pemerintah dan masyarakat membuat sanggar-sanggar taridan penari-penari yang ada di Sanggar Seni Sedulang Setudung semakin produktif dan mendapatkan finansial. Tari sedulang Setudung merupakan tari pokok tari yang biasanya pertama sekali di ajarkan untuk anak-anak baru yang masuk ke sanggar dan murid-murid baru yang ingin mengikuti ekstrakulikuler tari di sekolah mereka.

Perkembangan tari Sedulang Setudung di Kabupaten banyuasin juga tidak lepas dari adanya pengaruh luar. Modernisasi dan banyaknya transmigran yang datang ke Kabupaten Banyuasin menyebabkan sebuah akulturasi budaya yang berpengaruh pada kesenian yang ada termasuk tari Sedulang Setudung. Dengan adanya akulturasi tersebut tari Sedulang Setudung selain adanya budaya Melayu Islam yaitu suku asli banyuasin juga terdapat berbagai unsur budaya lain seperti halnya pada gerak tari. Gerak tari dalam tari Sedulang Setudung terdapat berbagai 
bentuk gerak yang mengadopsi dari gerak tari Gending Sriwijaya seperti gerak borobuddur dan jalan ngeset. Musik dalam tari Sedulang Setudung juga terdapat beberapa unsur modernisasi yaitu dengan ditambahkannya instrumen-instrumen musik modern seperi kerboard, bass, biola, gitar listrik dan drum. Hal tersebut merupakan bentuk respons dari tari Sedulang Setudung terhadap modernisasi untuk keberlangusan tari itu sendiri.

\section{PENUTUP}

Tari Sedulang Setudung merupakan tari penyambutan tamu di Kabupaten Banyuasin. Tari ini menggambarkan kebiasaan mayarakat Banyuasin. Tari Sedulang Setudung dibawakan oleh penari perempuan berjumlah ganjil Karena salah satu penari tersebut menjadi penari primadona yaitu sebagai pemegang tepak sirih yang akan diberikan kepada tamu agung yang datang.

Tari Sedulang Setudung telah mengalami perubahan pada bentuk pertunjukanya. Hal ini terlihat dari gerak tari, musik tari terdapat instrumen tambahan sehingga rasa atau suasana yang ditimbulkan berbeda, jumlah penari, dan properti tari Sedulang Setudung sekarang yang bersifat tentatif dan kostum tari yang digunakan lebih fleksibel tidak harus mengikuti pakem yang ada.

Perubahan pada tari Sedulang Setudung di Kabupaten Banyuasin merupakan tanggapan Seniman sebagai faktor internal terhadap sebuah tantangan yaitu faktor dari luar seperti pemerintah, masyarakat, budaya luar, ekonomi, dan pendidikan.
Tanggapan dari seniman terhadap tantangan yang ada menjadikan tari Sedulang Setudung di Kabupaten Banyuasin tetap berlangsung hingga saat ini.

\section{KEPUSTAKAAN}

Dewi, Heristina. 2016. "Keberlanjutan dan Perubahan Seni Pertunjukan Kuda Kepang di Sei Bamban, Serdang Bedagai, Sumatera Utara," Panggung Vol. 26 No. 2 (Juni 2016):140-150.

Gunawan, R. 2013."Sejarah Tari Persembahan Sedulang Setudung Kabupaten Banyuasin," Karya tulis. Pangkalan Balai, Banyuasin.

Hadi, Sumandiyo. 2003. Aspek-Aspek Dasar Koreografi Kelompok. Yogyakarta:ELKAPHI . 2007 . Kajian Tari Teks dan Konteks. Yogyakarta: Pustika BookPublisher.

Heriyandi. 2011. "Analisis Koreografi Tari Persembahan Sedulang Setudung Sebagai Tari Penyambutan Tamu Di Kabupaten Banyuasin" Skripsi S1. Palembang: Universitas PGRI Palembang.

2015. “Kreativitas Raden Gunawan dalam Penciptaan Tari Sedulang Setudung Kabupaten Banyuasin." tesis S-2 Program Studi Penciptaan dan Pengkajian Seni Minat Pengkajian Seni Tari Institut Seni Indonesia (ISI), Surakarta. 


\section{G마면지}

Koentjaraningrat. 1985. Pengantar Ilmu Antropologi. Jakarta: Aksara Baru.

Rustopo. 2001. Gendhon Humardani "Sang Gladiator". Yogyakarta: Yayasan Mahavhira.

Sedyawati, Edi, 1981. Pertumbuhan Seni Pertunjukan. Jakarta: Sinar Harapan

Slamet, MD. 2014. Barongan Blora Menari di Atas Politik dan Terpaan Zaman. Surakarta: Citra Sains LPKBN.
2016. Melihat tari. Surakarta: Citra Sains LPKBN.

Soedarsono. 1975. Komposisi Tari ElemenElemen Dasar. Yogyakarta: Akademi Seni Tari Indonesia.

1978. Pengantar Pengetahuan dan Komposisi Tari. Yogyakarta: Akademi Seni Tari Indonesia.

Syarofie, Yudhy. 2013. Tari Sambut di Sumatera Selatan. Palembang: Dinas Pendidikan Provinsi Sumatera Selatan. 